\title{
Injuries, Sequelae, and Treatment of Lightning-Induced Injuries: 10 Years of Experience at a Swiss Trauma Center
}

\author{
Carmen A. Pfortmueller, ${ }^{1}$ Yang Yikun, ${ }^{2}$ Monika Haberkern, ${ }^{2}$ Erwin Wuest, ${ }^{3}$ \\ Heinz Zimmermann, ${ }^{2}$ and Aristomenis K. Exadaktylos ${ }^{2}$ \\ ${ }^{1}$ University Department of General Internal Medicine, Inselspital Bern, 3010 Bern, Switzerland \\ ${ }^{2}$ University Department of Emergency Medicine, Inselspital Bern, 3010 Bern, Switzerland \\ ${ }^{3}$ Swiss Federal Statistical Office, 2000 Neuchâtel, Switzerland \\ Correspondence should be addressed to Aristomenis K. Exadaktylos, exadaktylos@exadaktylos.ch
}

Received 3 January 2012; Accepted 4 March 2012

Academic Editor: Robert W. Derlet

Copyright ( 92012 Carmen A. Pfortmueller et al. This is an open access article distributed under the Creative Commons Attribution License, which permits unrestricted use, distribution, and reproduction in any medium, provided the original work is properly cited.

\begin{abstract}
Principals. Lightning is one of the most powerful and spectacular natural phenomena. Lightning strikes to humans are uncommon but can cause devastating injuries. We analyzed lightning-related admissions to our emergency department from January 2000 to December 2010 to review and highlight the main features of lightning-related injuries. Methods. All data were collected prospectively and entered in the emergency department' database (Qualicare Switzerland) and retrospectively analyzed. Results. Nine patients with lightning-related injuries presented to our emergency department. Four were female, and five were male. The most common site of injury was the nervous system (6 out of 9 patients) followed by the cardiovascular system (5 out of 9 patients). The third most common injuries occurred to the skin ( 3 out of 9 patients). Four of the patients had to be hospitalized for further observation. Conclusion. Reports of lightning strikes and related injuries are scarce. The establishment of an international register would therefore benefit the understanding of their injury patterns and facilitate specific treatment.
\end{abstract}

\section{Introduction}

Lightning is one of the most powerful and spectacular natural phenomena [1]. It is the transfer of electrical charges between clouds or between the ground and clouds and occurs when a difference in potential of $30,000 \mathrm{~V}$ or higher exceeds the inherent resistance of the air [2]. Lightning strikes the earth more than 8 million times per day [3]. It is the second leading cause of weather-related death after flooding [4-6]. The risk of being struck by lightning is dependent on regional, seasonal and temporal factors [5, 7-9]. Lightning injuries peak during the summer months throughout the world $[5,7]$. Most lightning accidents occur outdoors [10]. People involved in golfing, fishing, swimming, boating, camping, or hiking are particularly at risk [10].

Reviews of lightning injuries have, however, found that one-third or more occur indoors $[9,11]$. As an injury mechanism, it is postulated that if lightning strikes a house, for example, the electrical energy can be transmitted through plumbing fixtures such as sinks, showers, or toilets [11]. According to a review by Lederer et al., about $10 \%$ of lightning injures occur during transport in motor vehicles [2]. Men are generally at greater risk of suffering lightning strikes than women $[2,4,10,12]$. In reviews, a male : female ratio of $5: 1$ was found $[7,11]$.

Lightning strikes in humans are an uncommon but potentially devastating cause of injury $[5,13,14]$. In contrast to other high-voltage accidents, lightning-related injuries involve not only extreme high voltages, but also very short exposure times to electrical current $[7,12,13,15]$. The injuries sustained may therefore not only be caused by electric energy, but also by high temperatures and blast waves [15] Lightning can affect the body in six physical ways: direct strike, contact voltage, side splash, step voltage, upward streamer, and blast injury [15] (Table 2).

Indirect hits by lightning strike are more common than direct strikes (Table 1) [10]. A case series reported by Cherington et al. with 13 incidents found side splashes to be 
TABLE 1: Types of lightning strike and ways they affect the human body.

\begin{tabular}{ll}
\hline Type & Mechanism \\
\hline Direct strike & Most of the current flows through the body; highest mortality \\
Contact voltage & Occurs when lightning strikes an object such as a car or metal pole that the victim is touching \\
Side flash & Splashing of current from a nearby object or person onto the victim \\
Ground current & Ground current passes from the strike point through the ground into the victim \\
Upward streamer & Passage of lightning from the victim upwards \\
Blast injury & Sudden expansive explosion of the air around the lightning channel causing blunt trauma \\
\hline
\end{tabular}

common [10]. Direct strikes are rare; they are responsible for about $5 \%$ of all lightning injuries and are often fatal $[10,13]$.

Mortality due to lightning is estimated to be $0.2-1.7$ deaths per million people per year worldwide $[5,7]$ and is highest in Africa [5]. The incidence of lightning strikes worldwide is estimated to be $0.09-0.12 / 100,000$ people [12]. In the UK, three people are killed annually by lightning strikes, and about 50 people are injured every year [1]. According to the Federal Statistics Agency of Switzerland, 42 people were struck by lightning between 1999 and 2009 with a mean of 3.8 per year (range 2-9) [16]. Four people were killed between 1998 and 2008 [14].

Lightning injury statistics are probably underestimated as people may not seek medical help $[5,6,9,12]$. Also, epidemiological data is not regularly recorded and evaluated in many countries [12]. Generally, the literature about lightning strikes and related injuries is scarce $[17,18]$. It consists largely of case reports and anecdotal reports $[17,18]$.

We analyzed lightning-related admissions to our emergency department from January 2000 to December 2010 to review and highlight their main features.

\section{Methods}

All data were collected prospectively and entered into the emergency department' centralized database (Qualicare, Switzerland) and retrospectively analyzed. The database was searched for patients aged $\geq 16$ years admitted between 1 January 2000 and 31 December 2010.

Patients scanned for the keyword "lightning strike" (German "Blitzschlag") were included in the analysis. Two cases with lightning strikes in their medical history that had not occurred during the study period were excluded.

Baseline demographic data (age, gender, nationality, profession) and the following clinical data were recorded: admission date, site of injury, and duration of hospital stay $(<24$ hours versus $\geq 24$ hours).

\section{Results}

During the study period, 9 patients presented to our emergency room because of lightning-related injury (Table 2) with a median age of 41 years (range $24-58$ years). Four were women (median age 31, range 24-32), and five were men (median age 49, range 41-58). All but one occurred on weekdays. Four people were struck outdoors: 1 on the street, 1 on a roof, and 2 in the mountains. A further 2 patients were hit while driving a car. Another patient was at home holding a copper panel when lightning struck. No site was recorded for two patients. Thus 3 of the 9 people were struck by lightning when in enclosed spaces such as a house or a car.

The most common site of injury was the nervous system ( 6 out of 9 patients) followed by the cardiovascular system (5 out of 9 patients). Table 2 shows details of injuries to the different organ systems. The most common neurological symptom was paresthesia which occurred in 4 cases. Two of these patients also had paralysis that resolved spontaneously. Further neurological symptoms were one case of vertigo, one of headache, and one of unreactive pupils.

Most of the cardiac symptoms were arrhythmias (4 out of 5 patients). One case of thoracic pain and one case of prehospital asystole with successful resuscitation with subsequent intermittent bradyarrhythmia were observed.

Three patients suffered skin injuries. Two patients sustained minor skin damage, and the third suffered secondand third-degree burns around the entry and exit wounds on his left chest and right-lower leg (9\% body surface area) and also had first-degree burns on the whole right-lower leg. One case of deafness following lightning-associated acoustic shock was found.

Three other injuries were observed: two cases of myoglobinuria, one in relation to severe burns and one in relation to paralysis. Additionally, one case of severe muscular contraction was observed. Four of the patients had to be hospitalized for further observation. Two of the four patients were admitted to ICU.

\section{Discussion}

4.1. Emergency Department Experience. Our study showed men to be at greater risk of suffering a lightning strike than females. Other studies confirm these findings $[2,4,13,17]$. Our patients were also older than the mean age in the literature, which reports that patients in their twenties and thirties have a higher risk of being struck by lightning $[4,13$, 17].

Most of our patients were struck outdoors. This finding is supported by others $[2,13,17]$.

Two of our patients were struck by lightning while sitting in a car. In the literature, a rate of $10 \%$ has been reported for this type of strike [2].

A review article by Slesinger et al. showed that damage to the nervous system occurs in up to $86 \%$ of cases [13]. The figures in our study were remarkably lower, and two 


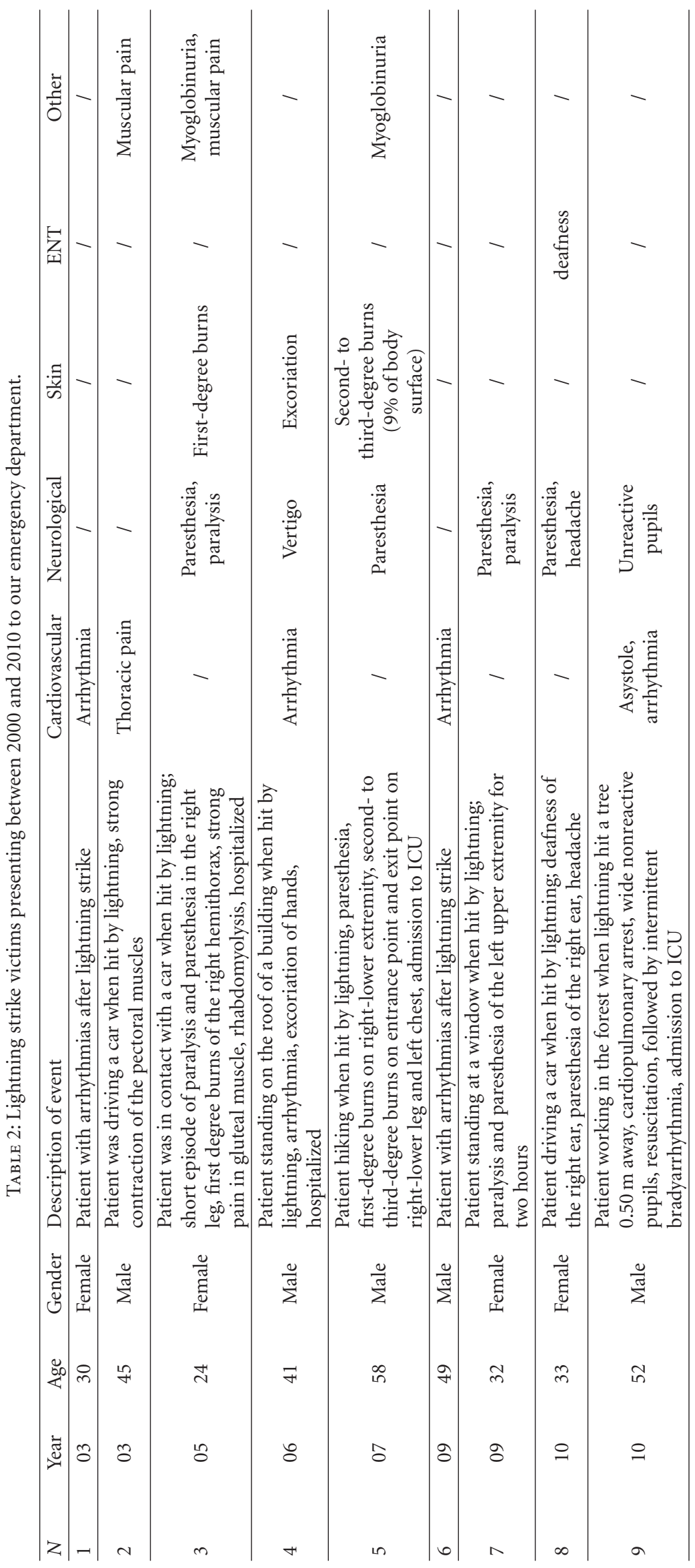


cases of paralysis and paresthesia were observed in our study. According to a case series of 13 patients reported by Conrad, about $80 \%$ of the lightning strike victims suffered from transient paralysis and paresthesia [17], a finding we cannot confirm. The cardiovascular system was second most commonly affected by lightning strikes in our case series. Figures in a review by Slesinger et al. were slightly higher than ours with a maximum of $46 \%$ of all patients having a cardiac problem after being struck by lightning [13]. Severe burns after lightning strikes are rare [2], as we also observed in our case series. Third-degree burns do, however, occurespecially at entry and exit burns - and were present in one of our patients [18]. One of our patients suffered from deafness, which is common in lighting strike victims [13]. Two of our patients had myoglobinuria which is not unusual in lightning strikes victims [13]. Two cases of severe skeletal muscular pain were observed in our study. This may be caused by sudden skeletal muscular contractions due to electrical shock [19].

\subsection{Risk Analysis}

4.2.1. Resuscitation. The immediate effects of lightning strike may cause asystole, ventricular fibrillation, or direct central nervous system injury to the respiratory center $[3,14]$. According to two reviews, the latter is very important because inherent automaticity of the cardiac conduction system often restores a perfusing rhythm $[5,11]$. Adequate ventilation is therefore as important as cardiac resuscitation because apnea may lead to secondary cardiac arrest [11]. According to a review by Conrad in the absence of resuscitative efforts, the duration of apnea may be a more important determinant of survival than the duration of asystole [17]. Furthermore, another review by Cherington found that lightning-related cardiac arrest occurs without any physical damage to the body in about $10 \%$ of cases [6]. They suggest that magnetic field changes associated with lightning may induce a loop current within the human torso [6]. If this loop occurs during the repolarization phase, asystole or ventricular fibrillation may occur [6]. Generally, resuscitation should be attempted on all lightning victims who appear lifeless because extraordinary recoveries even after prolonged resuscitation have been reported $[3,7,13]$. It is very important that wide unreactive pupils are not interpreted as a sign of a poor prognosis or brain death $[7,15]$.

4.2.2. Head and Nervous System. It is difficult to evaluate the severity and consequences of damage to deep organs and tissues caused by lightning strikes [14]. Generally, the extent of injuries from electric current are dependent on voltage, electrical tissue resistance, and duration of exposure [12].

Unlike skin, nervous tissue has very low electrical resistance $[2-4,12]$. According to a review by Duff and McCaffrey, nervous tissue is therefore particularly vulnerable to cell membrane damage when high voltages are applied for a short period, as with lightning strikes [4]. Damage to the cellular membranes of the nerves results in changes in cell permeability and protein denaturation which leads to cellular edema and potentially irreversible tissue damage [12]. Lightning strikes more often affect the central nervous system than the peripheral nerves $[10,11]$.

Furthermore, dysfunction of the autonomous nervous system may be induced, which leads to transient paralysis and paresthesia $[10,12]$. According to a review by Conrad, vasospasm of small blood vessels supplying the nerves may explain these symptoms [17]. The term "keraunoparalysis" has been used to describe short-term limb weakness associated with a hyperadrenergic state after a lightning strike [10]. The symptoms usually resolve in a matter of minutes or hours $[2,10,15]$. Permanent dysfunction of the sympathetic nervous system is rare [10]. In the case series reported by Cherington et al., $80 \%$ of lightning strike victims suffered from short episodes of paralysis and paresthesia without permanent damage [10].

Further neurological findings observed involve shortterm loss of consciousness, coma, seizures, headache, increased intracranial pressure, and intracranial hemorrhage $[2,11]$. The nervous system is the organ system most likely to suffer complications after lightning strike $[6,10]$. Delayed syndromes such as myelopathy or spinal muscular atrophy may occur weeks or even months after the lightning strike, and their exact mechanism is not known [10]. According to a review by Duff and McCaffrey, subtle cognitive impairments may be found [4].

Deafness is also common in lighting strike victims [12]. The most common cause is tympanic membrane rupture due to blast waves $[1,5,15]$. Further causes of ear injury may be barotrauma, burns, and vasomotor changes [15]. Injuries to the ear are often caused by using a telephone during a thunderstorm [9]. Acoustic injury from the loud crack of static electricity has been reported in people using a wireless phone handset with a hard-wired base during lightning [11].

4.2.3. Cardiovascular System. According to a review by Lederer et al., injuries of the cardiovascular system are common in lightning strike victims [2]. It has been found that the entire myocardium is depolarized when lightning strikes and that the heart remains in forced, sustained contraction until termination of the current $[2,13]$. This may cause cell necrosis, heart enzyme elevation, T-inversion, and QT prolongation similar to that reported after DC cardioversion or pacing [3]. Lightning strikes may also cause myocardial damage, pericardial effusion, conduction disturbances, and dysrhythmias $[2,3,13]$. Secondary damage to the myocardium may also occur due to catecholamine release or autonomic stimulation [2, 7]. Cardiac dysfunction, including severe biventricular failure, is often reversible $[3,13]$.

4.2.4. Skin. Reviews show that severe burns after lightning strikes are rare [2, 7]. Zafren et al. reported that superficial current often resembles skin flashover [19]. Internal current flow leading to deep tissue necrosis is uncommon [19]. Also, the extremely short duration of exposure to electrical current (0.0001-0.003 s) may prevent deep burns [11, 12]. Zafren et al. did, however, also report third-degree burns, especially at the entry and exit points of the electrical current [19]. 
4.2.5. Other Organ Injuries. Myoglobinuria is not an unusual finding in lighting strike victims [12]. Massive muscular contraction following electric shock may lead to release of myoglobin $[12,14]$, and renal failure may be precipitated by this $[2,12,14]$. According to Watanabe et al., serum creatine kinase levels are usually measured, but they never reflect the actual site and extent of the damage [14]. They may, however, be useful as a prognostic factor for the risk of acute renal failure [14].

Further injuries may be due to the sudden discharge of electrical energy causing the musculoskeletal muscles to contract forcefully, resulting in prostration or throwing the body several meters [11]. Furthermore, the rapid heating and cooling of the air around the strike causes an abrupt change in pressure, creating an explosion that may also propel the victim [11]. This may result in fractures, joint dislocation, or blunt trauma $[2,4,12]$. Falling debris such as tree trunks may also cause additional injuries [10].

4.2.6. Prognosis. Zafren et al. reported that $70 \%$ of lightning strikes are not fatal [19]. They usually last only milliseconds and flash over the victim's body with minimal transfer of energy to the internal organs [13]. Lederer suggested that immediate total cessation of cellular metabolic activity following lightning strike delays the onset of anoxic degenerative processes and therefore may be responsible for the good prognosis of lightning-induced resuscitation [12]. The same mechanism may also reduce the potential for irreversible neurologic damage and may be responsible for complete neurological recovery following even prolonged resuscitation [12]. Furthermore, as the patients are mostly young, prearrest morbidity usually is low $[5,17]$.

According to Zafren et al., persons who are stunned or lose consciousness without cardiorespiratory arrest are unlikely to die [19]. Three-quarters of survivors, however, have permanent sequelae such as tinnitus, seizures, and blindness $[7,19]$.

4.2.7. Limitations. Our study was retrospective and therefore relied on medical records which were not always complete and did not include long-term follow-up information. Only few data were available for some of our patients. Standardized data was therefore not obtained, and bias cannot be excluded. Cases presenting to our hospital may have been underreported as children are treated in a separate emergency department.

\section{Conclusion}

The patterns of clinical signs and symptoms in lightning strikes injuries are rare, are substantially different from those in common electrical accidents because extremely high voltages with brief exposure are involved, and are associated with substantial morbidity. They are therefore challenging for the attending medical team. The nervous and cardiovascular systems are especially vulnerable to damage from lightning strike. Because lightning strikes are rare, the establishment of an international register would benefit the understanding of their injury patterns and facilitate specific treatment.

\section{Authors' Contribution}

Y. Yang and A. C. Pfortmueller were responsible for acquisition, analysis, and interpretation of data. Drafting of the manuscript was done by A. C. Pfortmueller and A. K. Exadaktylos. M. Haberkern, H. Zimmermann, and A. Exadaktylos contributed to this work by providing critical revision of the manuscript for important intellectual content. Administrative, technical, and material support were provided by E. Wuest, H. Zimmermann, and A. K. Exadaktylos. A. K. Exadaktylos supervised the study. Prof. Dr. A. K. Exadaktylos had full access to all data in the study and the accuracy of the data analysis.

\section{References}

[1] V. Cooray, C. Cooray, and C. J. Andrews, "Lightning caused injuries in humans," Journal of Electrostatics, vol. 65, no. 5-6, pp. 386-394, 2007.

[2] W. Lederer, F. J. Wiedermann, E. Cerchiari, and M. A. Baubin, "Electricity-associated injuries II: outdoor management of lightning- induced casualties," Resuscitation, vol. 43, no. 2, pp. 89-93, 2000.

[3] R. Lichtenberg, D. Dries, K. Ward, W. Marshall, and P. Scanlon, "Cardiovascular effects of lightning strikes," Journal of the American College of Cardiology, vol. 21, no. 2, pp. 531536, 1993.

[4] K. Duff and R. J. McCaffrey, "Electrical injury and lightning injury: a review of their mechanisms and neuropsychological, psychiatric, and neurological sequelae," Neuropsychology Review, vol. 11, no. 2, pp. 101-116, 2001.

[5] A. E. Ritenour, M. J. Morton, J. G. McManus, D. J. Barillo, and L. C. Cancio, "Lightning injury: a review," Burns, vol. 34, no. 5, pp. 585-594, 2008.

[6] M. Cherington, "Neurologic manifestations of lightning strikes," Neurology, vol. 60, no. 2, pp. 182-185, 2003.

[7] J. S. O. Hinkelbein and W. A. Wetsch, "Blitzschlag und Blitzunfälle in der präklinischen Notfallmedizin: Relevanz, Folgen und praktische Implikationen," Der Unfallchirurg. In press.

[8] "Part 8: advanced challenges in resuscitation. Section 3: special challenges in ECC. 3G: electric shock and lightning strikes. European Resuscitation Council," Resuscitation, vol. 46, no. 13, pp. 297-299, 2000.

[9] D. M. Elsom, "Deaths and injuries caused by lightning in the United Kingdom: analyses of two databases," Atmospheric Research, vol. 56, no. 1-4, pp. 325-334, 2000.

[10] M. Cherington, P. R. Yarnell, and S. F. London, "Neurologic complications of lightning injuries," Western Journal of Medicine, vol. 162, no. 5, pp. 413-417, 1995.

[11] J. J. Mistovich, W. S. Krost, and D. D. Limmer, "Beyond the basics: lightning-strike injuries," EMS Magazine, vol. 37, no. 3, pp. 82-89, 2008.

[12] W. K. G. Lederer, "Notfallmedizinische Versorgung von Blitzund Stromschlagverletzungen," Anaesthesist, vol. 51, no. 11, pp. 1120-1129, 2005.

[13] T. L. Slesinger, M. Bank, B. C. Drumheller et al., "Immediate cardiac arrest and subsequent development of cardiogenic shock caused by lightning strike," Journal of Trauma, vol. 68, no. 1, pp. E5-E7, 2010.

[14] N. Watanabe, T. Inaoka, N. Shuke et al., "Acute rhabdomyolysis of the soleus muscle induced by a lightning strike: magnetic 
resonance and scintigraphic findings," Skeletal Radiology, vol. 36, no. 7, pp. 671-675, 2007.

[15] Z. Fred, "Blitzunfall-Energieübertragungsmechanismen und medizinische Folgen," Deutsches Ärzteblatt, vol. 104, no. 51-52, pp. 3545-3549, 2007.

[16] BSF, http://www.bfs.admin.ch/bfs/portal/de/index/themen/ 14/04/01/data/01/01.html.

[17] L. Conrad, "Clinical update on lightning injuries," Wilderness and Environmental Medicine, vol. 9, no. 4, pp. 217-222, 1998.

[18] T. Muehlberger, P. M. Vogt, and A. M. Munster, "The longterm consequences of lightning injuries," Burns, vol. 27, no. 8, pp. 829-833, 2001.

[19] K. Zafren, B. Durrer, J. P. Herry, and H. Brugger, "Lightning injuries: prevention and on-site treatment in mountains and remote areas: official guidelines of the International Commission for Mountain Emergency Medicine and the Medical Commission of the International Mountaineering and Climbing Federation (ICAR and UIAA MEDCOM)," Resuscitation, vol. 65 , no. 3, pp. 369-372, 2005. 


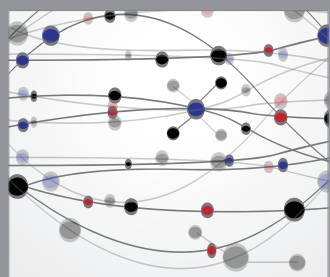

The Scientific World Journal
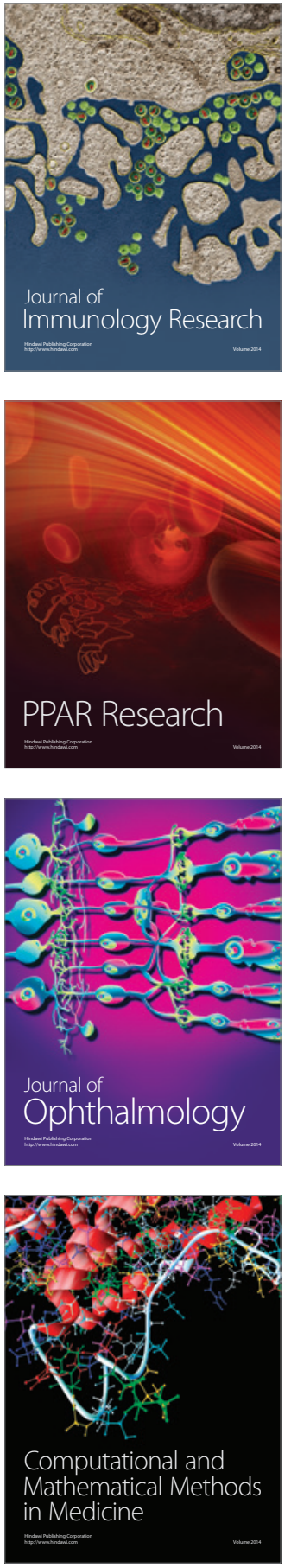

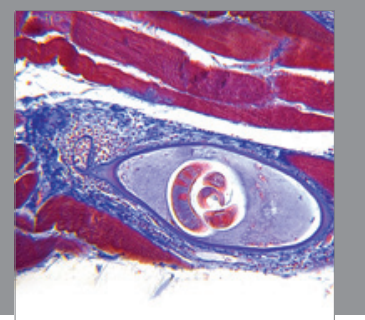

Gastroenterology

Research and Practice
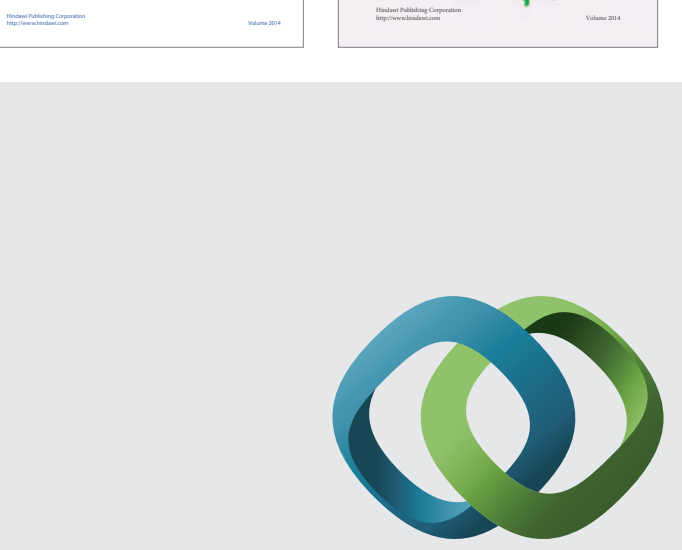

\section{Hindawi}

Submit your manuscripts at

http://www.hindawi.com
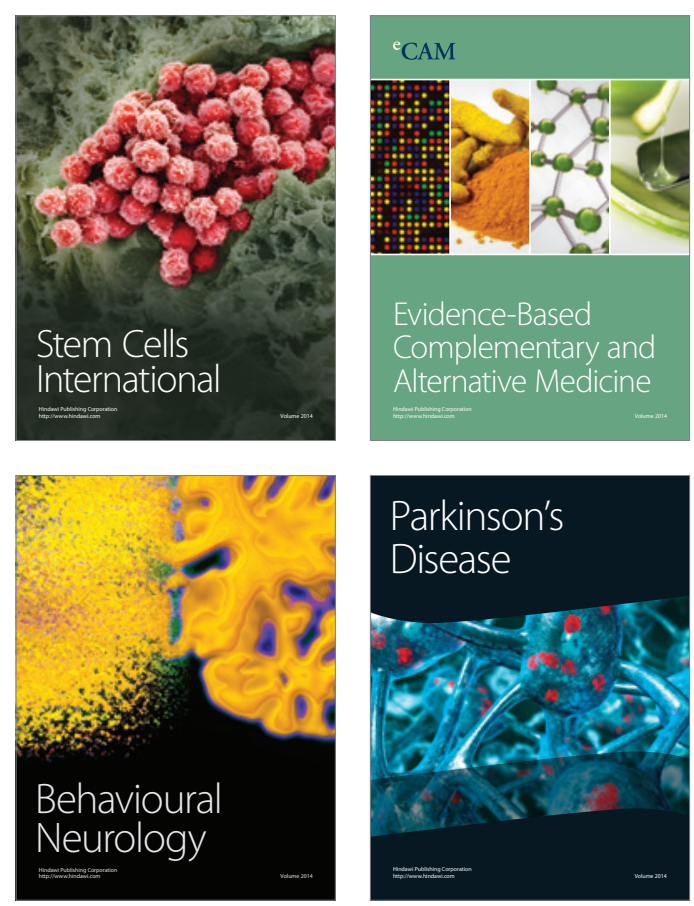

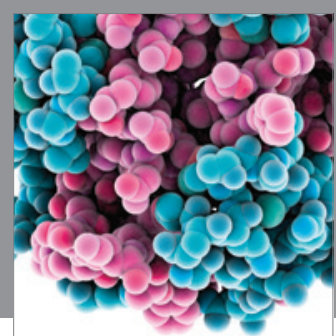

Journal of
Diabetes Research

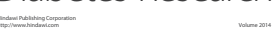

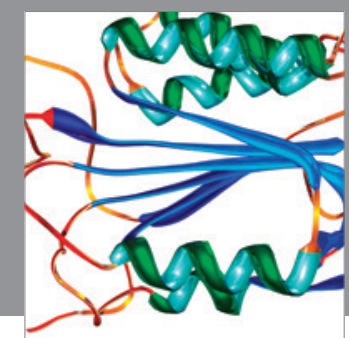

Disease Markers
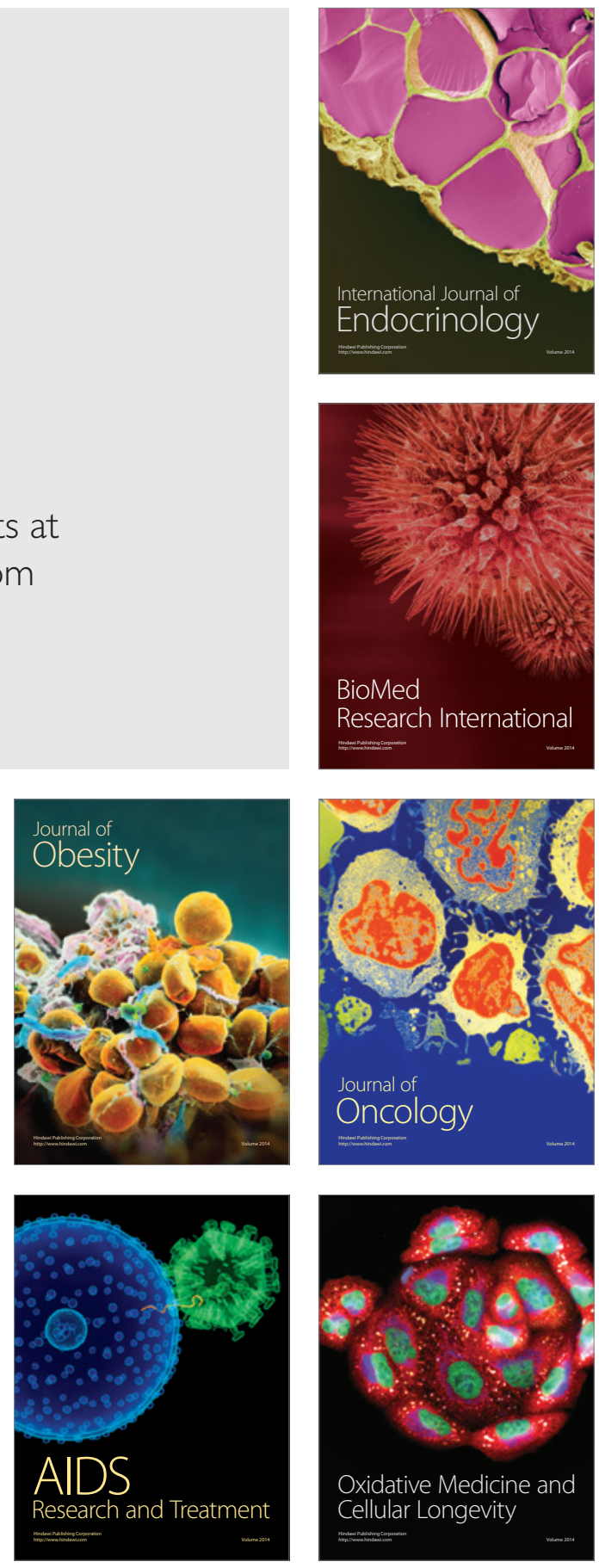